\title{
Prevalence of Albuminuria and Cardiovascular Risk Profile in a Referred Cohort of Patients with Type 2 Diabetes: An Asian Perspective
}

\author{
C.Y. Pan, M.D., ${ }^{1}$ L.T. Ho, M.D., ${ }^{2}$ S. Soegondo, Sp.P.D.-K.E.M.D., F.A.C.E., ${ }^{3}$ \\ W. Prodjosudjadi, Ph.D., Sp.P.D.-K.G.H., ${ }^{3}$ S. Suwanwalaikorn, M.D., ${ }^{4}$ \\ S.C. Lim, M.B.B.S., M.R.C.P. (UK), F.A.M.S. (Singapore), ${ }^{5}$ \\ T.M. Chan, M.D. (HK), F.R.C.P. (London, Edinburgh, and Glasgow), F.H.K.C.P., F.H.K.A.M. (Medicine), ${ }^{6}$ \\ K.W. Steven Chow, M.B.B.S. (Malaya), F.R.C.P.I., ${ }^{7}$ M. Thoenes, M.D., ${ }^{8}$ \\ and D.S. Choi, M.D. ${ }^{9}$ on behalf of the DEMAND Study Investigators
}

\begin{abstract}
Background: Microalbuminuria (MA) is a risk marker for diabetic nephropathy and cardiovascular (CV) disease (CVD) in patients with diabetes. This study aimed to describe the prevalence of albuminuria, CV risk factors, and treatments for renal and CV protection in an Asian population with type 2 diabetes.

Methods: This cross-sectional study conducted in eight Asian countries enrolled normotensive/hypertensive adults with type 2 diabetes without known proteinuria and/or non-diabetic kidney disease. Exclusion criteria were type 1 diabetes, menstruation, pregnancy, and acute fever. A single random urinary albumin/creatinine test was carried out in all patients.

Results: Of 8,561 patients, $14 \%$ had diabetic retinopathy, and $17 \%$ and $21 \%$ had history of CV disease and smoking, respectively. Normoalbuminuria was seen in $44 \%$, MA in $44 \%$, and macroalbuminuria in $12 \%$. Target glycosylated hemoglobin $(\mathrm{HbA} 1 \mathrm{c})(<7 \%)$ was reached in only $37 \%$ of 3,834 patients with available values. Diabetes was managed by diet alone in $6 \%$, while others received oral hypoglycemic drugs and/or insulin. In total, $75 \%$ did not reach target blood pressure (BP) of $\leq 130 / 80 \mathrm{~mm} \mathrm{Hg}$. Antihypertensive drugs were prescribed to $52 \%$, with the number of drugs increasing as the level of systolic BP increased. Drugs blocking the renin-angiotensin system were most commonly prescribed, followed by calcium channel blockers. Lipid-lowering drugs and anticoagulant/antiplatelet agents were used in about $30 \%$ and $25 \%$ of patients, respectively.

Conclusions: Asian patients with type 2 diabetes had a high prevalence of MA and reduced kidney function. Furthermore, BP and $\mathrm{HbA1c}$ control was only achieved in a minority of patients. Aggressive risk management by administration of reno- and cardioprotective treatments is urgently needed.
\end{abstract}

\section{Introduction}

$\mathbf{M}$ ICROALBUMINURIA (MA), which is defined as an abnormal increase in the rate of urinary excretion of albumin to between 30 and $300 \mathrm{mg} / 24 \mathrm{~h}$, was first described in patients with diabetes mellitus in $1969 .{ }^{1}$ It is the earliest man- ifestation of diabetic kidney disease in both type 1 and type 2 diabetes and a strong risk marker for the progression of nephropathy. ${ }^{2}$ Several prospective epidemiologic studies have also demonstrated that MA is an important risk factor for cardiovascular (CV) disease (CVD) in patients with type 2 diabetes. A meta-analysis of these studies showed that the

\footnotetext{
${ }^{1}$ Chinese PLA General Hospital, Beijing, People's Republic of China.

${ }^{2}$ Taipei Veterans General Hospital, Taipei, Republic of China.

${ }^{3}$ Ciptomangunkusumo General Hospital, Jakarta, Indonesia.

${ }^{4}$ King Chulalongkorn Memorial Hospital, Bangkok, Thailand.

${ }^{5}$ Alexandra Hospital, Singapore.

${ }^{6}$ Department of Medicine, University of Hong Kong, Queen Mary Hospital, Hong Kong.

${ }^{7}$ Pantai Medical Centre, Kuala Lumpur, Malaysia.

${ }^{8}$ sanofi-aventis, Paris, France.

${ }^{9}$ Korea University Medical Center, Seoul, Republic of Korea.
} 
presence of MA doubled the risk of CV morbidity or mortality. ${ }^{3}$

Besides its role in diabetic nephropathy, MA is also associated with essential hypertension, ${ }^{4}$ ischemic heart disease, ${ }^{5}$ atherosclerosis, ${ }^{6}$ acute stroke, ${ }^{7}$ and diastolic dysfunction ${ }^{8}$ and is an independent powerful risk factor for fatal and nonfatal vascular events and all-cause mortality in subjects without diabetes. ${ }^{9,10}$ In fact, Ibsen et al. ${ }^{11}$ showed that a reduction in urinary albumin excretion was associated with a reduction in CV events in hypertensive patients treated with blockade of the renin-angiotensin system (RAS).

In the last 4 decades, the knowledge about MA and its implications has grown significantly. Guidelines such as the ones produced by the American Diabetes Association (ADA) recommend annual screening for MA in patients with diabetes. ${ }^{12}$ However, since MA is not associated with clinical symptoms, it is often underdiagnosed, and the awareness of its importance as renal and CV risk marker is still poor. Several interventional studies aiming at improved glycemic control and blockade of the RAS have shown that the onset of diabetic nephropathy can be postponed in patients with type 2 diabetes with normoalbuminuria and/or MA. ${ }^{13-15}$ Despite the knowledge about early identification and intervention in high-risk patients with type 2 diabetes, diabetic nephropathy is still the leading cause of end-stage renal disease in most countries of the world. ${ }^{16}$ Thus, it is critically important to identify incident kidney disease in patients with diabetes at the earliest stage by screening for MA in order to best prevent evolution to overt nephropathy and subsequent endstage renal disease.

In 2003, the International Diabetes Federation and the International Society of Nephrology developed the theme "Diabetes could cost you your kidneys: act now!" In collaboration with these organizations, a study was created on Developing Education on Microalbuminuria for Awareness of Renal and CV risk in Diabetes (DEMAND). This cross-sectional, global, clinic/medical center-based study described the prevalence and risk factors for MA and implementation of CV protective treatment in normotensive and hypertensive patients with type 2 diabetes without known proteinuria and/or kidney disease not due to diabetes. ${ }^{17}$ We present here data from Asia, including the People's Republic of China, Hong Kong, Indonesia, the Republic of Korea, Malaysia, Singapore, the Republic of China, and Thailand.

\section{Materials and Methods}

\section{Study design}

The DEMAND study was a multinational, cross-sectional, clinic/medical center-based study designed to evaluate the prevalence and determinants of MA and macroalbuminuria in patients with type 2 diabetes by random screening at each participating center during the interval from June to September 2003. The goal was to enroll 10 patients with type 2 diabetes per center. The study was mainly performed in primary care settings. The study was endorsed and the centers selected by local diabetes associations in collaboration with Bristol-Myers Squibb (New York, NY) and sanofi-aventis (Paris, France). A total of eight different countries in Asia, including the People's Republic of China (50 sites), Hong Kong (74 sites), Indonesia (30 sites), the Republic of Korea (20 sites), Malaysia (50 sites), Singapore (97 sites), Republic of China (14 sites), and Thailand (nine sites) participated. The study protocol was approved by the Ethics Committee of each participating clinic, and all patients gave written informed consent.

\section{Patients}

Eligible patients were normotensive or hypertensive women and men between 18 and 80 years with type 2 diabetes mellitus (World Health Organization criteria) without prior known proteinuria and/or kidney disease due to diabetes. Exclusion criteria included type 1 diabetes mellitus, menstruation, pregnancy, and acute fever.

Concomitant medications such as cimetidine (which may falsely elevate creatinine levels) and drugs containing azo dyes, nitrofurantoin, and riboflavin (which affect the readability of the reagent strips) were prohibited. Contamination of the urine specimen with soaps, detergents, antiseptics, or skin cleansers or the use of urine preservatives other than boric acid $(1.0 \mathrm{~g} / \mathrm{L})$ was also restricted.

\section{Investigations}

All participating general practitioners, physicians, and nurses received the study protocol and were instructed in performing the urinary albumin/creatinine test (single determination) and blood pressure (BP) measurement with an appropriate cuff after approximately $10 \mathrm{~min}$ of rest in the sitting position (single recording).

Furthermore, demographic profile (age, gender, ethnicity, and region), clinical characteristics (height, body mass index [BMI], known duration of diabetes, glycosylated hemoglobin $[\mathrm{HbA} 1 \mathrm{c}]$, and serum creatinine), medical history (retinopathy, diabetic foot lesion, CVD, smoking, hyperlipidemia, and family history of diabetes/hypertension/CVD), and simultaneous treatments (glucose-lowering treatment, antihypertensive agents, lipid-lowering drugs, and antiplatelet/anticoagulant agents) for each patient were recorded on a single-page clinical report form.

Presence of CVDs such as coronary artery disease, myocardial infarction, left ventricular hypertrophy, congestive heart failure, stroke, transient ischemic attack, or peripheral vascular disease was based on medical records and information obtained during the interview. Standardized definitions of the different CVDs were not applied. Presence of hyperlipidemia was based on objective measurements as stated in the medical records. Presence of arterial hypertension was based on medical history of patients receiving BP-lowering therapy.

A single random urine albumin/creatinine ratio was measured using Bayer reagent strip Multistix ${ }^{\circledR}$ 10SG (Siemens Medical Solutions Diagnostics, Tarrytown, NY and Los Angeles, CA). According to this semiquantitative strip test, normoalbuminuria is defined as albumin-to-creatinine ratio $<30$ $\mathrm{mg} / \mathrm{g}$, MA as 30-299 $\mathrm{mg} / \mathrm{g}$, and macroalbuminuria as $\geq 300$ $\mathrm{mg} / \mathrm{g}$. According to the manufacturer, the Multistix 10SG test has a sensitivity of $84 \%$ and specificity of $91 \%$ for the albumin-to-creatinine ratio. Urine samples with concentrations of creatinine of $\leq 10 \mathrm{mg} / \mathrm{dL}$ were discarded as too dilute, as prespecified in the protocol.

We used the Modification of Diet in Renal Disease 2 formula to calculate the estimated glomerular filtration rate (eGFR) (in $\left.\mathrm{mL} / \mathrm{min} / 1.73 \mathrm{~m}^{2}\right) .{ }^{18}$ The stages of chronic kidney 
disease were defined according to the American National Kidney Foundation: stage 1, eGFR $\geq 90$; stage 2, eGFR 60-89; stage 3, eGFR 30-59; stage 4, 15-29; and stage 5, eGFR <15 or dialysis. ${ }^{19}$ Patients in stage 1 and 2 needed to have structural or functional abnormalities of the kidney, for example, $\mathrm{MA} /$ macroalbuminuria, to be classified as having chronic kidney disease. An eGFR of $<60 \mathrm{~mL} / \mathrm{min} / 1.73 \mathrm{~m}^{2}$ is defined as renal insufficiency.

\section{Statistical analysis}

Univariate comparisons of the impact of independent variables on the average levels of continuous and categorical dependent variables were made using one-way analysis of vari-

Table 1. Characteristics of Patients With TYPE 2 DiABETES

\begin{tabular}{|c|c|c|}
\hline Characteristics $(\mathrm{n}=8,561)$ & $\mathrm{n}$ & $\%$ \\
\hline \multicolumn{3}{|l|}{ Demographic } \\
\hline \multicolumn{3}{|l|}{ Countries and regions } \\
\hline People's Republic of China & 4,238 & 50 \\
\hline Hong Kong & 403 & 5 \\
\hline Indonesia & 770 & 9 \\
\hline Republic of Korea & 184 & 2 \\
\hline Malaysia & 181 & 2 \\
\hline Singapore & 499 & 6 \\
\hline Republic of China & 1,648 & 19 \\
\hline Thailand & 638 & 7 \\
\hline \multicolumn{3}{|l|}{ Gender } \\
\hline Male & 4,208 & 49 \\
\hline Female & 4,314 & 50 \\
\hline Missing & 39 & $<1$ \\
\hline Age (years) $($ mean $\pm S D)$ & $60.2 \pm 11.6$ & \\
\hline $20 \mathrm{~s}$ & 63 & 1 \\
\hline $30 \mathrm{~s}$ & 323 & 4 \\
\hline $40 \mathrm{~s}$ & 1,279 & 15 \\
\hline $50 s$ & 2,333 & 27 \\
\hline $60 \mathrm{~s}$ & 2,579 & 30 \\
\hline $70 \mathrm{~s}$ & 1,688 & 20 \\
\hline $80 s$ & 178 & 2 \\
\hline Missing & 118 & 1 \\
\hline \multicolumn{3}{|l|}{ Ethnicity } \\
\hline White & 2 & $<1$ \\
\hline Black & 1 & $<1$ \\
\hline Asian & 7,842 & 92 \\
\hline Hispanic & 0 & 0 \\
\hline Other & 0 & 0 \\
\hline Missing & 716 & 8 \\
\hline \multicolumn{3}{|l|}{ Clinical $(n=8,561)$} \\
\hline BMI $\left(\mathrm{kg} / \mathrm{m}^{2}\right)$ & $24.7 \pm 3.9$ & \\
\hline Missing & 116 & 1 \\
\hline Duration of diabetes (years) & $7.3 \pm 6.2$ & \\
\hline Missing & 642 & 8 \\
\hline HbA1c $(\%)$ & $7.8 \pm 1.8$ & \\
\hline Missing & 4,727 & 55 \\
\hline \multicolumn{3}{|l|}{ Medical history $(n=8,561)$} \\
\hline Family history of diabetes & 3,234 & 38 \\
\hline Family history of CVD & 1,490 & 17 \\
\hline Smoking history & 1,794 & 21 \\
\hline History of hyperlipidemia & 3,276 & 38 \\
\hline History of CVD & 1,461 & 17 \\
\hline History of retinopathy & 1,217 & 14 \\
\hline History of diabetic foot & 314 & 4 \\
\hline
\end{tabular}

Table 2. Medical Treatment in Patients With TYPe 2 DiABETES

\begin{tabular}{ll}
\hline Treatment & $\mathrm{n}$
\end{tabular}

Glucose-lowering

Diet-alone

$514 \quad 6$

Oral hypoglycemic agent

$6,577 \quad 77$

Insulin

Both oral hypoglycemic agent and insulin

$637 \quad 7$

Missing

7749

Antihypertensive treatment

On no antihypertensive medications $\quad 4,110 \quad 48$

$\begin{array}{lrr}\text { Diuretics } & 891 & 10\end{array}$

ACEI $\quad 1,905 \quad 22$

ARB $\quad 735 \quad 9$

Calcium channel blockers $\quad 1,902 \quad 22$

Alpha blockers

Other antihypertensive agents

$\begin{array}{ll}190 & 2 \\ 367 & 4\end{array}$

Lipid-lowering agents

$1,521 \quad 18$

$\begin{array}{lll}\text { Other lipid-lowering agents } & 1,016 & 12\end{array}$

$\begin{array}{lr}\text { On anticoagulant/antiplatelet agents } & 1,809 \quad 21 \\ \text { Aspirin }\end{array}$

Warfarin $\quad 28<1$

On other anticoagulant/antiplatelet agents $\quad 273 \quad 3$

$\mathrm{ACEI}$, angiotensin-converting enzyme inhibitor; $\mathrm{ARB}$, angiotensin receptor blocker.

ance and the $\chi^{2}$ statistic, respectively. A minimal multivariate model predicting the level of albuminuria (normal albuminuria, MA, or macroalbuminuria) was constructed using "proportional odds" ordinal logistic models as realized by the function lrm for S. ${ }^{19}$ Parallel models predicting the albumin/creatinine ratio (log transformed) as a continuous variable were built using ordinary linear regression models and gave comparable results. To build these models, independent variables were added to the model in the order in which they increased the total likelihood of the model, taken as a measure of explanatory power, until no further additions significantly $(P<0.05)$ improved the likelihood, using the likelihood ratio test. All data management was performed using SAS for Windows version 9.0 (SAS Institute, Cary, NC), and all analyses were performed using S-Plus version 6.2 for Windows (Insightful Corp., Seattle, WA).

\section{Results}

A total of 8,561 patients were included in the study. Their characteristics are shown in Table 1 . Overall, the mean age was 60 years, the gender distribution was 50/50, and the mean duration of diabetes was 7.3 years. Diabetic retinopathy was present in $14 \%$, while $17 \%$ had history of CVD, and $21 \%$ had history of smoking. The mean $\mathrm{HbA} 1 \mathrm{c}$ was $7.8 \%$ (data missing for $55 \%$ of patients), and $\mathrm{HbA} 1 \mathrm{c}$ was at target level $(<7 \%)$ in only $37 \%$ of 3,834 patients for whom the values were available.

Medical treatments received by patients are presented in Table 2 . Only $6 \%$ of patients with type 2 diabetes were managed with diet alone, whereas the remaining received oral hypoglycemic drugs and/or insulin. Among the 8,561 patients, $250(3 \%)$ had missing data with regard to antihypertensive drug use. Antihypertensive drugs were prescribed to 
4,451 (52\%) patients. Drugs blocking the RAS, followed by calcium channel blockers and diuretics, were most commonly used. The number of BP-lowering drugs prescribed increased with the level of systolic BP (SBP). The percentage of patients not receiving antihypertensive medication dropped from approximately $36 \%$ at a SBP of $140 \mathrm{~mm} \mathrm{Hg}$ to approximately $14 \%$ at a SBP of $200 \mathrm{~mm} \mathrm{Hg}$. Only 30\% of patients received lipid-lowering drugs, and anticoagulant/antiplatelet agents were given to about $25 \%$ of patients.

Normoalbuminuria was demonstrated in $44 \%$ and MA in $44 \%$, and the remaining $12 \%$ had macroalbuminuria (Table 3). Overall, eGFR averaged $78 \pm 127 \mathrm{~mL} / \mathrm{min} / 1.73 \mathrm{~m}^{2}$ (data missing in $67 \%$ of patients). In the subset of patients with data permitting estimation of glomerular filtration rate $(n=$ $2,841), 23 \%$ had renal insufficiency, that is, eGFR $<60$ $\mathrm{mL} / \mathrm{min} / 1.73 \mathrm{~m}^{2}$. While $61 \%$ of patients did not achieve target SBP $(<130 \mathrm{~mm} \mathrm{Hg}), 62 \%$ did not achieve target diastolic $\mathrm{BP}(\mathrm{DBP})<80 \mathrm{~mm} \mathrm{Hg}$. In total, $6,250(75 \%)$ had $\mathrm{SBP} \geq 130$ $\mathrm{mm} \mathrm{Hg}$ and/or DBP $\geq 80 \mathrm{~mm} \mathrm{Hg}$.

\section{Discussion}

In this Asian cross-sectional study of patients with type 2 diabetes without previously known proteinuria or kidney disease, approximately $56 \%$ had MA or macroalbuminuria. Although serum creatinine data were missing in two-third of our patients, renal insufficiency was detected in $23 \%$ of those with available data. This large clinic/medical centerbased study confirms and extends previous observations suggesting a high prevalence of MA in several Asian countries. ${ }^{20-22}$ Our results highlight the need for more regular and earlier testing of MA to detect the presence of kidney disease due to diabetes. In fact, based on abundant evidence showing that MA predicts both renal and CV outcomes in patients with diabetes and in the general population, the latest European guidelines now include MA in routine testing because it is simple and cheap and has good predictive value. $^{23}$

The main strength of our study was that it included a large, multinational referred cohort of subjects with type 2 diabetes

Table 3. Albuminuria, Kidney Function, and Arterial BP in Patients with Type 2 Diabetes

\begin{tabular}{lcc}
\hline Variable & Value & $\%$ \\
\hline Albuminuria & & \\
None & 3,794 & 44 \\
MA & 3,753 & 44 \\
Macroalbuminuria & 1,014 & 12 \\
Log 2 (albumin/creatinine ratio) & $37(2.9-467)^{\mathrm{a}}$ & \\
$\quad$ (mg of albumin/g of creatinine) & $1.01 \pm 0.40$ & \\
Serum creatinine (mg/dL) & 5,700 & 67 \\
Missing & $78 \pm 127$ & \\
MDRD GFR (mL/min) & 5,720 & 67 \\
Missing & $133 \pm 18$ & \\
SBP (mm Hg) & 250 & 3 \\
Missing & $79 \pm 10$ & \\
DBP (mm Hg) & 258 & 3 \\
Missing & \\
\hline
\end{tabular}

MDRD GFR, modification of diet in renal disease glomerular filtration rate.

aThe $95 \%$ confidence interval is given in parentheses. in Asia with validated identification of predefined primary and secondary end points. Although there are other singlecountry studies assessing kidney function, ${ }^{20-22}$ there are very few large multinational studies on MA in Asian subjects with diabetes and hypertension. ${ }^{24}$ Moreover, our study enrolled a higher number of Asian patients and was part of a much larger global study to establish worldwide prevalence and risk factors of MA in patients with diabetes. Our study also had some limitations. First, we carried out only a single measurement of urinary albumin/creatinine ratio and arterial BP. However, the large sample size and the high frequency of diagnostic abnormality detected with a single urine collection minimize the uncertainty associated with day-to-day differences in urinary albumin excretion, and single measurement has been shown to be a useful tool for assessing MA in large epidemiological studies. A second limitation was that since we only looked at patients' historical data on lipids and $\mathrm{HbA} 1 \mathrm{c}$ values, there was no standardized method for determining these values. Although cigarette smoking is a strong and modifiable risk factor for macrovascular disease in patients with diabetes, ${ }^{25}$ we did not collect data on current smoking history. An additional limitation that may potentially confound the results of this regional analysis is the fact that almost $50 \%$ of patients were contributed by the Republic of China alone. Hence, because of unequal representation from different countries, the results may not be uniformly applicable to the eight participating Asian countries. Since our study was not population-based, there is a possibility of selection bias in relation to the participating centers. However, the prevalence of MA or macroalbuminuria in our study $(56 \%)$ is comparable with $58.6 \%$ observed in a crosssectional study of consecutively screened 5,549 patients with type 2 diabetes from 10 Asian countries. ${ }^{24}$

Our study revealed an increased prevalence of several vascular risk factors. Patients with type 2 diabetes have a two to six times higher risk of fatal and non-fatal CV events than subjects without diabetes.3,26,27 Patients with MA and macroalbuminuria suffer the highest risk, possibly because of several modifiable risk factors such as hypertension, dyslipoproteinemia, and increased platelet aggregability. Randomized double-blind trials in patients with type 2 diabetes demonstrated benefits of intensified intervention involving a single vascular risk factor on macro- and microvascular disease. ${ }^{27-30}$ The Steno-2 study revealed that an intensified, targeted, multifactorial intervention aimed at several modifiable risk factors in patients with type 2 diabetes and MA reduced the risk of $\mathrm{CV}$ and microvascular events by about half. ${ }^{31,32}$ The latest scientific statement from the American Heart Association (AHA) and the ADA for the primary prevention of CVD in people with diabetes also recommends comprehensive risk assessment and broad-based treatment of risk factors. ${ }^{32}$

The average $\mathrm{HbA1c}$ in our study was lower than that reported in the intensive treatment arm of the Steno- 2 study. ${ }^{31}$ However, values were missing in $63 \%$ of our patients. Only $37 \%$ patients (of 3,834 with $\mathrm{HbA1c}$ values) achieved target $\operatorname{HbA1c}(<7 \%)$, attesting the fact that in some cases the management of glycemia was less aggressive than desired. Among those with the highest $\mathrm{HbA1c}$ levels, many patients were not started on insulin therapy.

A target $\mathrm{BP}$ of $<130 / 80 \mathrm{~mm} \mathrm{Hg}$ is recommended in patients with type 2 diabetes. ${ }^{34}$ In our study, the majority of 
patients had uncontrolled BP, and yet almost half of these patients did not receive BP-lowering therapy, despite the well-documented benefit on large and small vessel disease. ${ }^{35}$ A study by Ramirez et al. ${ }^{36}$ suggested that the association between SBP or DBP and proteinuria did not seem to have a minimal threshold level because a trend for an increase in odds for proteinuria was observed even with BP measurements within the recommended range. The fact that even mild BP elevations were associated with proteinuria in a multi-ethnic population from Singapore might suggest that normal BP values for Asians are not equivalent to those established for Caucasians and indicates the need to establish BP nomograms specific to the Asian population. ${ }^{36}$ The most frequently used antihypertensive drugs were agents blocking the RAS, followed by calcium channel blockers. The AHA-ADA guidelines recommend an antihypertensive regimen containing an angiotensin-converting enzyme inhibitor or an angiotensin-receptor blocker. ${ }^{32}$ Nonetheless, even these drugs were utilized in only $30 \%$ of our patients. A combination of drugs is often needed for adequate BP control in patients with diabetes - although angiotensin-converting enzyme inhibitors and angiotensin-receptor blockers are the preferred first-line agents, a low-dose thiazide diuretic generally should be one of the first two drugs used. ${ }^{32}$ However, diuretics were underused (only 10\%) in our study. While the emphasis is on tight BP control to reduce morbidity, the actual choice of drug should be individually decided by the physician. ${ }^{37}$ Since most patients in our study were only on one or two classes of antihypertensive agents even at the highest SBP, the treatment of hypertension needs to be more aggressive.

Several statin trials have demonstrated a beneficial effect on CV events, including ischemic stroke, in patients with type 2 diabetes. ${ }^{28,29,38}$ Furthermore, since these drugs are safe, there is a strong argument that type 2 diabetes patients warrant statin treatment. ${ }^{39}$ Although $38 \%$ patients had history of hyperlipidemia, lipid-lowering therapy was only recorded in $30 \%$ of patients, despite these patients having a high frequency of several conventional CV risk factors including MA and macroalbuminuria. Even among patients with a history of hyperlipidemia, only $38 \%$ received statins.

A large meta-analysis of the use of antiplatelet agents clearly indicates a CV benefit in diabetes. ${ }^{40}$ Low-dose therapy with aspirin (or another antiplatelet agent) is recommended as a primary prevention strategy in those with diabetes at increased CV risk, including those who are $<40$ years of age or who have additional risk factors (family history of CVD, hypertension, smoking, dyslipidemia, or albuminuria). ${ }^{33}$ While a large proportion of patients in our study had one or more of these risk factors, only one-fourth of the patients received antiplatelet agents.

To summarize, there is a high prevalence of MA and macroalbuminuria and reduced kidney function, conditions associated with adverse renal and CV events, in Asian patients with type 2 diabetes without prior known nephropathy. MA is known to be more prevalent in South Asian individuals than in white Europeans, which is consistent with the observation that they are at greater risk for CV complications compared to white Europeans. ${ }^{41,42}$ A study by Dixon et al. ${ }^{42}$ showed that almost one-third of South Asian patients with diabetes having untreated normal BP had MA. This increased prevalence of MA, even in normotensive subjects, suggests that the threshold for intervention and the target for therapy of CV risk factors in South Asian patients with type 2 diabetes should be lower than for white Europeans. ${ }^{42}$ In conclusion, early detection of MA, monitoring of vascular complications, and more aggressive multifactorial treatment aiming at renal and vascular protection are urgently needed.

\section{Acknowledgments}

We thank all patients for their participation in the DEMAND study. We thank doctors, nurses, and administrative staff in hospitals, general practices, and site-managed organizations that assisted with the study. The study was supported by Bristol-Myers Squibb and sanofi-aventis. The sponsors of the study (Bristol-Myers Squibb and sanofiaventis) contributed to the study design and data collection and reviewed and commented on drafts. The sponsors had no role in data analysis, data interpretation, or writing the report. The corresponding author had full access to all data in the study and had final responsibility for the decision to submit for publication. M.T. is affiliated with sanofiaventis.

\section{References}

1. Keen H, Chlouverakis C, Fuller J, Jarrett RJ: The concomitants of raised blood sugar: studies in newly-detected hyperglycaemics. II. Urinary albumin excretion, blood pressure and their relation to blood sugar levels. Guy's Hosp Rep 1969;118:247-254.

2. Williams ME: Diabetic nephropathy: the proteinuria hypothesis. Am J Nephrol 2005;25:77-94.

3. Dinneen SF, Gerstein HC: The association of microalbuminuria and mortality in non-insulin-dependent diabetes mellitus: a systematic overview of the literature. Arch Intern Med 1997;157:1413-1418.

4. Parving H-H, Mogensen CE, Jensen Hí, Evrin P-E: Increased urinary albumin-excretion rate in benign essential hypertension. Lancet 1974;i:1190-1192.

5. Jensen JS, Feldt-Rasmussen B, Strandgaard S, Schroll M, Borch-Johnsen K: Arterial hypertension, microalbuminuria, and risk of ischemic heart disease. Hypertension 2000;35: 898-903.

6. Jørgensen L, Jenssen T, Johnsen SH, Mathiesen EB, Heuch I, Joakimsen O, Fosse E, Jacobsen BK: Albuminuria as risk factor for initiation and progression of carotid atherosclerosis in non-diabetic persons: the Tromso Study. Eur Heart J 2007;28:363-369.

7. Turaj W, S`owik A, Wyrwicz-Petkow U, Pankiewicz J, Iskra T, Rudziñska M, Szczudlik A: The prognostic significance of microalbuminuria in non-diabetic acute stroke patients. Med Sci Monit 2001;7:989-994.

8. Grandi AM, Santillo R, Bertolini A, Imperiale D, Broggi R, Colombo S, Selva E, Jessula A, Guasti L, Venco A: Microalbuminuria as a marker of preclinical diastolic dysfunction in never-treated essential hypertensives. Am J Hypertens 2001;14:644-648.

9. Yudkin JS, Forrest RD, Jackson CA: Microalbuminuria as predictor of vascular disease in non-diabetic subjects. Lancet 1988;ii:530-533.

10. Borch-Johnsen K, Feldt-Rasmussen B, Strandgaard S, Schroll M, Jensen JS: Urinary albumin excretion. An independent predictor of ischemic heart disease. Arterioscler Thromb Vasc Biol 1999;19:1992-1997. 
11. Ibsen $\mathrm{H}$, Olsen $\mathrm{MH}$, Wachtell $\mathrm{K}$, Borch-Johnsen $\mathrm{K}$, Lindholm LH, Mogensen CE, Dahlöf B, Devereux RB, de Faire U, Fyhrquist F, Julius S, Kjeldsen SE, Lederballe-Pedersen O, Nieminen MS, Omvik P, Oparil S, Wan Y: Reduction in albuminuria translates to reduction in cardiovascular events in hypertensive patients: losartan intervention for endpoint reduction in hypertension study. Hypertension 2005;45:198202.

12. American Diabetes Association: Standards of medical care in diabetes-2007. Diabetes Care 2007;30(Suppl 1):S4-S41.

13. UK Prospective Diabetes Study (UKPDS) Group: Intensive blood-glucose control with sulphonylureas or insulin compared with conventional treatment and risk of complications in patients with type 2 diabetes (UKPDS 33). Lancet 1998; 352:837-853.

14. Ruggenenti P, Fassi A, Ilieva AP, Bruno S, Ilieva IP, Brusegan V, Rubis N, Gherardi G, Arnoldi F, Ganeva M, Ene-Iordache B, Gaspari F, Perna A, Bossi A, Trevisan R, Dodesini AR, Remuzzi G; the Bergamo Nephrologic Diabetes Complications Trial (BENEDICT) Investigators: Preventing microalbuminuria in type 2 diabetes. N Engl J Med 2004;351: 1941-1951.

15. Parving H-H, Lehnert H, Bröchner-Mortensen J, Gomis R, Andersen S, Arner P; the Irbesartan in Patients with Type 2 Diabetes and Microalbuminura Study Group: The effect of irbesartan on the development of diabetic nephropathy in patients with type 2 diabetes. N Engl J Med 2001;345:870878.

16. Parving H-H, Mauer M, Ritz E: Diabetic nephropathy. In: Brenner BM, ed. Brenner and Rector's The Kidney. Boston: W.B. Saunders, 2004:1777-1818.

17. Parving H-H, Lewis JB, Ravid M, Remuzzi G, Hunsicker LG; the DEMAND Investigators: Prevalence and risk factors for microalbuminuria in a referred cohort of type II diabetic patients: a global perspective. Kidney Int 2006;69:2057-2063.

18. National Kidney Foundation: K/DOQI clinical practice guidelines for chronic kidney disease. Evaluation, classification, and stratification. Am J Kidney Dis 2002;39(Suppl): S1-S266.

19. Harrell FE: Regression Modelling Strategies. New York: Springer, 2001.

20. Hatthachote P, Suwan K, Pongmanee K, Areekul W: Albuminuria in rural Thai people: a community-based screening with Combur Test and Micral Test strips. J Med Assoc Thai 2005;88(Suppl 3):S164-S174.

21. Tam TK, Cheng LP, Lau DM, Lai TC, Lai WY, Ng KK, Ng MY, Kong CW, Tsang LC: The prevalence of microalbuminuria among patients with type II diabetes mellitus in a primary care setting: cross-sectional study. Hong Kong Med J 2004;10:307-311.

22. Lu B, Wen J, Song XY, Dong $X H$, Yang $Y H$, Zhang ZY, Zhao NQ, Ye HY, Mou B, Chen FL, Liu Y, Shen Y, Wang XC, Zhou LN, Li YM, Zhu XX, Hu RM: High prevalence of albuminuria in population-based patients diagnosed with type 2 diabetes in the Shanghai downtown. Diabetes Res Clin Pract 2007;75:184-192.

23. Mancia G, De Backer G, Dominiczak A, Cifkova R, Fagard R, Germano G, Grassi G, Heagerty AM, Kjeldsen SE, Laurent S, Narkiewicz K, Ruilope L, Rynkiewicz A, Schmieder RE, Boudier HA, Zanchetti A: 2007 guidelines for the management of arterial hypertension: the Task Force for the Management of Arterial Hypertension of the European Society of Hypertension (ESH) and of the European Society of Cardiology (ESC). J Hypertens 2007;25:1105-1187.
24. Wu AY, Kong NC, de Leon FA, Pan CY, Tai TY, Yeung VT, Yoo SJ, Rouillon A, Weir MR; the MAPS Investigators: An alarmingly high prevalence of diabetic nephropathy in Asian type 2 diabetic patients: the MicroAlbuminuria Prevalence (MAP) Study. Diabetologia 2005;48:17-26.

25. Haire-Joshu D, Glasgow RE, Tibbs TL: Smoking and diabetes. Diabetes Care 2004;27(Suppl 1):S74-S75.

26. Gall MA, Borch-Johnsen K, Hougaard P, Nielsen FS, Parving H-H: Albuminuria and poor glycemic control predict mortality in NIDDM. Diabetes 1995;44:1303-1309.

27. Gerstein HC, Mann JF, Yi Q, Zinman B, Dinneen SF, Hoogwerf B, Hallé JP, Young J, Rashkow A, Joyce C, Nawaz S, Yusuf S; the HOPE Study Investigators: Albuminuria and risk of cardiovascular events, death, and heart failure in diabetic and nondiabetic individuals. JAMA 2001;286:421-426.

28. UK Prospective Diabetes Study (UKPDS) Group: Efficacy of atenolol and captopril in reducing risk of macrovascular and microvascular complications in type 2 diabetes: UKPDS 39. UK Prospective Diabetes Study Group. BMJ 1998;317:713720.

29. Pyörälä K, Pedersen TR, Kjekshus J, Faergeman O, Olsson AG, Thorgeirsson G; the Scandinavian Simvastatin Survival Study (4S) Group: Cholesterol lowering with simvastatin improves prognosis of diabetic patients with coronary heart disease. A subgroup analysis of for the Scandinavian Simvastatin Survival Study (4S). Diabetes Care 1997;20:614-620.

30. Heart Outcomes Prevention Evaluation (HOPE) Study Investigators: Effects of ramipril on cardiovascular and microvascular outcomes in people with diabetes mellitus: results of the HOPE study and MICRO-HOPE substudy. Lancet 2000;355:253-259.

31. Gëde P, Vedel P, Larsen N, Jensen GV, Parving H-H, Pedersen O: Multifactorial intervention and cardiovascular disease in patients with type 2 diabetes. N Engl J Med 2003;348: 383-393.

32. Gëde P, Vedel P, Parving H-H, Pedersen O: Intensified multifactorial intervention in patients with type 2 diabetes mellitus and microalbuminuria: the Steno type 2 randomised study. Lancet 1999;353:617-622.

33. Buse JB, Ginsberg HN, Bakris GL, Clark NG, Costa F, Eckel R, Fonseca V, Gerstein HC, Grundy S, Nesto RW, Pignone MP, Plutzky J, Porte D, Redberg R, Stitzel KF, Stone NJ; American Heart Association; American Diabetes Association: Primary prevention of cardiovascular diseases in people with diabetes mellitus: a scientific statement from the American Heart Association and the American Diabetes Association. Diabetes Care 2007;30:162-172.

34. Chobanian AV, Bakris GL, Black HR, Cushman WC, Green LA, Izzo Jr JL, Jones DW, Materson BJ, Oparil S, Wright JT Jr, Roccella EJ; the National High Blood Pressure Education Program Coordinating Committee: The Seventh Report of the Joint National Committee on Prevention, Detection, Evaluation, and Treatment of High Blood Pressure. JAMA 2003;289:2560-2571.

35. Arauz-Pacheco C, Parrott MA, Raskin P: Hypertension management in adults with diabetes. Diabetes Care 2004;27 (Suppl 1):S65-S67.

36. Ramirez SP, McClellan W, Port FK, Hsu SI: Risk factors for proteinuria in a large, multiracial, Southeast Asian population. J Am Soc Nephrol 2002;13:1907-1917.

37. Ong HT, Cheah JS: Choice of antihypertensive drug in the diabetic patient. MedGenMed 2005;7:74.

38. Heart Protection Study Collaborative Group: MRC/BHF Heart Protection Study of cholesterol lowering with sim- 
vastatin in 20536 high-risk individuals: a randomised placebo-controlled trial. Lancet 2002;360:7-22.

39. Colhoun HM, Betteridge DJ, Durrington PN, Hitman GA, Neil HA, Livingstone SJ, Thomason MJ, Mackness MI, Charlton-Menys V, Fuller JH; the CARDS Investigators: Primary prevention of cardiovascular disease with atorvastatin in type 2 diabetes in the Collaborative Atorvastatin Diabetes Study (CARDS): multicentre randomised placebo-controlled trial. Lancet 2004;364:685-696.

40. Antithrombotic Trialists' Collaboration: Collaborative metaanalysis of randomised trials of antiplatelet therapy for prevention of death, myocardial infarction, and stroke in high risk patients. BMJ 2002;324:71-86.

41. Fischbacher CM, Bhopal R, Rutter MK, Unwin NC, Marshall SM, White M, Alberti KGMM: Microalbuminuria is more frequent in South Asian than in European origin popula- tions: a comparative study in Newcastle, UK. Diabet Med 2003;20:31-36.

42. Dixon AN, Raymond NT, Mughal S, Rahim A, O'Hare JP, Kumar S, Barnett AH: Prevalence of microalbuminuria and hypertension in South Asians and white Europeans with type 2 diabetes: a report from the United Kingdom Asian Diabetes Study (UKADS). Diabetes Vasc Dis Res 2006;3:22-25.

Address reprint requests to:

C.Y. Pan, M.D.

Department of Endocrinology Chinese PLA General Hospital

28 Fu Xin Road

Beijing, People's Republic of China, 100853

E-mail: panchy301@yahoo.com.cn 